\title{
Retrograde entry portal for femoral interlocking nailing in femoral nonunion after plate failure: a prospective comparative study with antergrade portal
}

\author{
Yasser Assaghir ${ }^{1}$
}

Received: 5 June 2015/ Accepted: 26 June 2016/Published online: 20 July 2016

(c) The Author(s) 2016. This article is published with open access at Springerlink.com

\begin{abstract}
The piriformis fossa is the ideal portal of entry for antegrade interlocking nailing. Localizing this portal can be difficult and its eccentricity leads to complications. This prospective comparative study was designed to compare an innovative way to obtain the ideal portal from inside the medullary canal in cases of plate failure and compare it to the classic antegrade portal. It included 41 cases (19 antegrade and 22 retrograde). The retrograde portal was significantly better in terms of entry time, radiation time, blood-loss, and wound length. The proper portal was rapidly and easily achieved in all retrograde cases without complications; while four in antegrade cases had complications. Minimum follow-up was 2 years.

Level of evidence III.
\end{abstract}

Keywords Failed plate fixation - Interlocking nail femur . Retrograde portal of entry · Antegrade nailing $\cdot$ Femoral nonunion

\section{Introduction}

There are two portals of entry for antegrade femoral interlocking nailing; they are the greater trochanter and the piriformis fossa. The trochanteric tip should be reserved for

Yasser Assaghir

youryaser@yahoo.com; youryaser@gmail.com;

youryaser@live.com

1 Orthopaedic Department, Sohag Faculty of Medicine, Sohag University, Sohâg 82425, Egypt nails with a proximal bend specially designed for the trochanteric portal [1]. The piriformis starting point appears to be the best, as the piriformis fossa tends to align with the longitudinal axis of the medullary canal [2]. Obtaining this ideal point can be technically difficult especially in obese patients, requires long radiation exposure, and its eccentricity can have serious consequences, specially its anterior shift [1-3]. We hypothesized we can provide an alternative technique surgery by making use of the open nature of surgery for plate failure, which must be removed, and obtain the ideal portal from inside the proximal fragment.

\section{Materials and methods}

This study included patients with femur nonunion between 2010 and 2013. The inclusion and exclusion criteria are shown on Table 1. Forty-four cases were eligible; three were lost for follow-up; and 41 were categorized into two groups; antegrade 19 cases, and retrograde 22 cases. The inclusion into either group was based on the sequence of admission number. The demographics of the patients, nonunion, and fracture demographics are shown in Tables 2 and 3.

\section{Operative technique}

Retrograde portal: hardware was removed. The AO $9 \mathrm{~mm}$ end-cutting reamer was introduced from the refreshed nonunion site over the reamer guide rod. After perforating the piriformis fossa, the reamer guide rod was received through a mini proximal wound (Fig. 1). The antegrade portal was done using the classic technique (Fig. 2). We used a Russell-Taylor first generation nail in all cases. 
Table 1 Inclusion and exclusion criteria

\begin{tabular}{ll}
\hline Inclusion criteria & Exclusion criteria \\
\hline 1. Nonunion after plating & 1. Septic nonunion \\
$\begin{array}{l}\text { 2. Treatment with reamed } \\
\text { interlocking nailing }\end{array}$ & $\begin{array}{c}\text { 2. Plate failure after } \\
\text { pathological fractures }\end{array}$ \\
$\begin{array}{l}\text { 3. Two years minimum follow-up } \\
\end{array}$ & \\
\hline
\end{tabular}

We calculated blood loss during the whole surgery, entry portal time, radiation time, and proximal incision length. Postoperative plain X-rays were requested to assess nail, locking screws, reduction, and centricity of the nail portal.

Table 2 The demographics of patients and nonunion are shown

\begin{tabular}{|c|c|c|c|c|}
\hline Parameter & \multicolumn{2}{|l|}{ Group } & Mean \pm SD & $P$ value \\
\hline \multirow[t]{2}{*}{ Age } & \multicolumn{2}{|c|}{ Antergrade $(n=19)$} & $37.1 \pm 11.5$ & 0.516 \\
\hline & \multicolumn{2}{|c|}{ Retrograde $(n=22)$} & $38.1 \pm 10.8$ & \\
\hline \multirow[t]{4}{*}{ Sex } & \multirow[t]{2}{*}{ Antergrade } & Male & $11(57.9 \%)$ & 0.479 \\
\hline & & Female & $8(42.1 \%)$ & \\
\hline & \multirow[t]{2}{*}{ Antergrade } & Male & $12(54.5 \%)$ & \\
\hline & & Female & $10(45.5 \%)$ & \\
\hline \multirow[t]{2}{*}{ Weight (kg) } & \multicolumn{2}{|l|}{ Antergrade } & $84.2 \pm 5.5$ & 0.105 \\
\hline & \multicolumn{2}{|l|}{ Retrograde } & $79.1 \pm 6.6$ & \\
\hline \multirow[t]{4}{*}{ Side } & \multirow[t]{2}{*}{ Antergrade } & Right & $11(57.9 \%)$ & 0.163 \\
\hline & & Left & $8(42.1 \%)$ & \\
\hline & \multirow[t]{2}{*}{ Retrograde } & Right & $9(40.9 \%)$ & \\
\hline & & Left & $13(59.1 \%)$ & \\
\hline \multirow[t]{6}{*}{ Level } & \multirow[t]{3}{*}{ Antergrade } & Upper third & $5(26.3 \%)$ & 0.096 \\
\hline & & Middle third & $13(68.4 \%)$ & \\
\hline & & Lower third & $1(5.3 \%)$ & \\
\hline & \multirow[t]{3}{*}{ Retrograde } & Upper third & 0 & \\
\hline & & Middle third & $20(90.9 \%)$ & \\
\hline & & Lower third & $2(9.1 \%)$ & \\
\hline \multirow[t]{4}{*}{ Comminution } & \multirow[t]{2}{*}{ Antergrade } & Comminuted & $10(52.6 \%)$ & 0.314 \\
\hline & & $\begin{array}{l}\text { Non- } \\
\text { comminuted }\end{array}$ & $9(47.4 \%)$ & \\
\hline & \multirow[t]{2}{*}{ Retrograde } & Comminuted & $9(40.9 \%)$ & \\
\hline & & $\begin{array}{l}\text { Non- } \\
\text { comminuted }\end{array}$ & $13(59.1 \%)$ & \\
\hline \multirow[t]{6}{*}{ Shape } & \multirow[t]{3}{*}{ Antegrade } & Transverse & $8(42.1 \%)$ & 0.254 \\
\hline & & Oblique & $8(42.1 \%)$ & \\
\hline & & Spiral & $3(15.8 \%)$ & \\
\hline & \multirow[t]{3}{*}{ Retrograde } & Transverse & $5(22.7 \%)$ & \\
\hline & & Oblique & $7(31.8 \%)$ & \\
\hline & & Spiral & $10(45.5 \%)$ & \\
\hline \multirow{2}{*}{$\begin{array}{l}\text { Time to plate } \\
\text { failure }\end{array}$} & Antergrade & \multicolumn{2}{|c|}{$12.0 \pm 5.2(4-26)$ weeks } & 0.813 \\
\hline & Antergrade & \multicolumn{2}{|c|}{$11.3 \pm 4.7(4-24)$ weeks } & \\
\hline
\end{tabular}

Table 3 The frequency of fractures according to OTA classification

\begin{tabular}{lll}
\hline OTA type & Antegrade & Retrograde \\
\hline $32-\mathrm{A} 1.1$ & 1 & 2 \\
$32-\mathrm{A} 1.2$ & 2 & 2 \\
$32-\mathrm{A} 1.3$ & 0 & 0 \\
$32-\mathrm{A} 2.1$ & 1 & 0 \\
$32-\mathrm{A} 2.2$ & 2 & 3 \\
$32-\mathrm{A} 2.3$ & 2 & 2 \\
$32-\mathrm{A} 3.1$ & 1 & 0 \\
$32-\mathrm{A} 3.2$ & 4 & 6 \\
$32-\mathrm{A} 3.3$ & 1 & 2 \\
$32-\mathrm{B} 1.1$ & 0 & 0 \\
$32-\mathrm{B} 1.2$ & 0 & 0 \\
$32-\mathrm{B} 2.1$ & 2 & 1 \\
$32-\mathrm{B} 2.2$ & 3 & 5 \\
$32-\mathrm{B} 2.3$ & 0 & 4 \\
\hline
\end{tabular}

$P$ value between both groups was 0.249

\section{Statistical analysis}

Data was shown in the form of mean $\pm \mathrm{SD}$ and range. Paired sample $t$ test, one-way ANOVA, and Pearson test were conducted to detect significant differences between groups. All statistical analyses were done using the SPSS program (SPSS 15.0, SPSS Inc., IL, USA).

\section{Results}

Table 4 and Fig. 3 show the final outcome in both groups. There were significant differences in favor of retrograde portal in terms of entry time, in radiation time, in bloodloss, and proximal wound length.

Proper centric entry was achieved in all cases of retrograde portal and 15 cases of antegrade portal with three cases having lateral shift of portal; and one medial shift (Fig. 4). There was a significant correlation between frontal angulation and the presence of comminuted fractures, as well eccentric portal of entry. Table 5 shows the factors causing varus/valgus angulation; Table 6 shows their statistical significance.

The Pearson test detected significant correlations between the type of portal and entry time, radiation time, blood-loss, and wound length (Table 7).

\section{Complications}

Four cases in the antegrade portal group had eccentric portal: three with lateral shift had a varus angulation $\left(5^{\circ}-\right.$ $7^{\circ}$ ) at the nonunion site; and one medial shift had a valgus of $5^{\circ}$ angulation. 


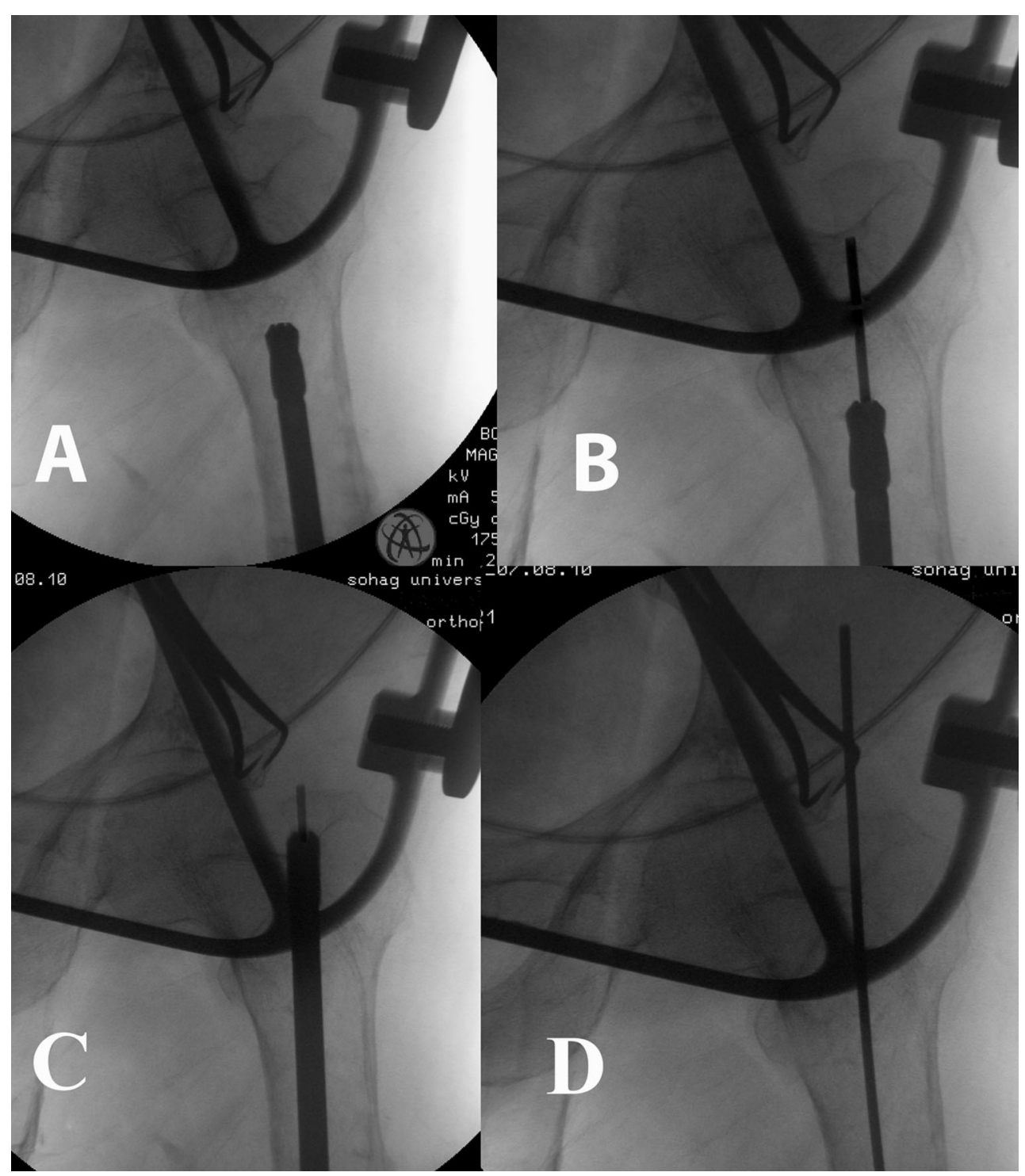

Fig. 1 a The introduction of the reamer up the medullary canal. b The reamer guide-rod inserted through the reamer. c Perforation of the piriformis fossa from within the medullary canal. d The reamer is removed and the reamer guide-rod is exiting from the portal

\section{Discussion}

Accomplishing closed reduction and locating the entry portal for nail insertion are the two most important steps in femoral interlocking nailing procedures [2]. The entry point has significant consequences for the ease of insertion and the strength of fixation [3].

There are two entry portals for antegrade femoral interlocking nailing: the piriformis fossa and the trochanteric portal [4]. A piriformis entry (ideally just posterior to its center) appears to be the best, as it tends to align with the longitudinal axis of the medulla $[2,5,6]$. Its disadvantages are the relative technical difficulty compared with retrograde and trochanteric portals [7]. The trochanteric portal is the tip of greater trochanter and its use is limited to nails with a proximal bend for paediatric fractures [8]. The trochanteric-tip portal has a much greater potential of iatrogenic proximal femoral fractures during nail insertion [9]. Both portals do not affect the perfusion of the femoral head [10].

This study tried to test the use of a novel method of obtaining the proper piriformis portal from inside the 
Fig. 2 a Perforating the piriformis fossa with an awl. b Introducing the reamer guiderod into the medullary canal in antegrade cases
Table 4 Results with comparison between the two groups
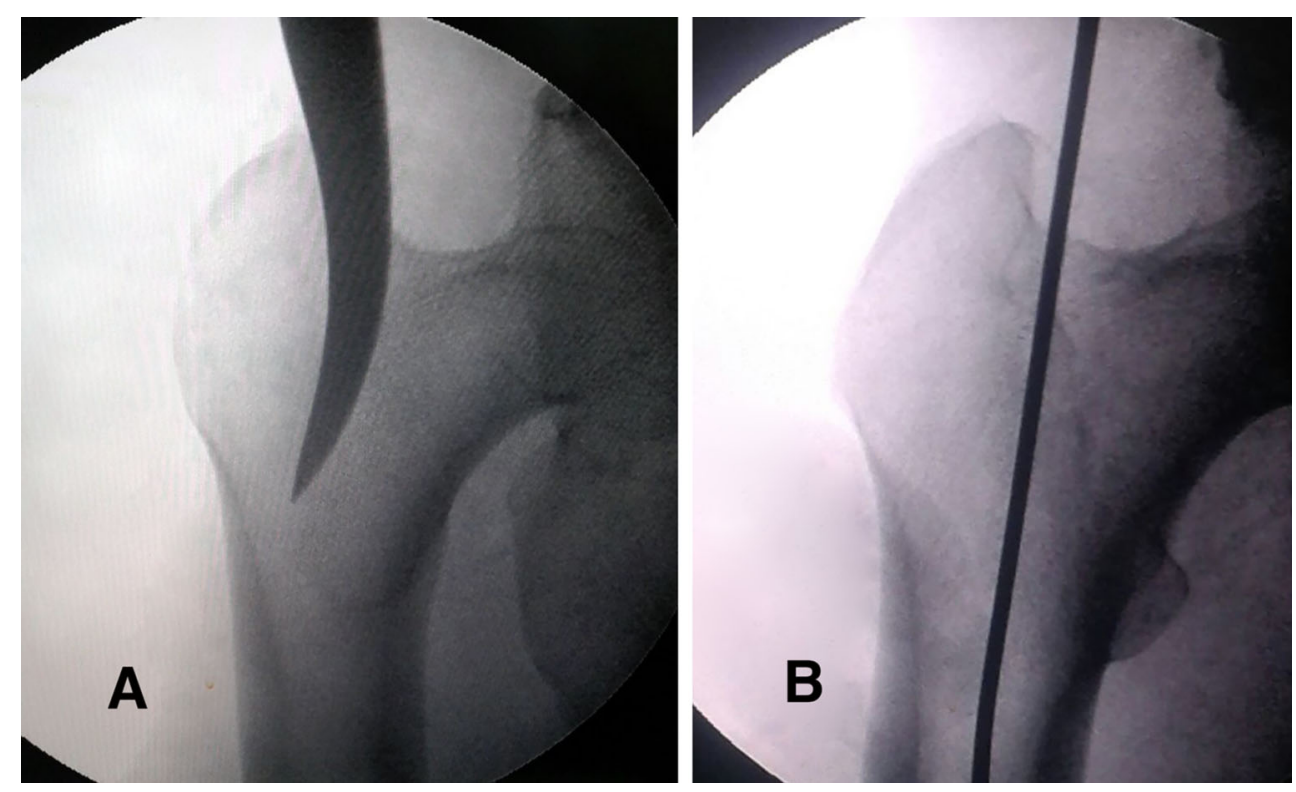

\begin{tabular}{|c|c|c|c|c|c|}
\hline Parameter & Mean & SD & Minimum & Maximum & $P$ value \\
\hline \multicolumn{6}{|l|}{ Eccentricity } \\
\hline Antergrade $(n=19)$ & 0.4 & 1.0 & 0.0 & 4.0 & \multirow[t]{2}{*}{0.069} \\
\hline Retrograde $(n=22)$ & 0.0 & 0.0 & 0.0 & 0.0 & \\
\hline \multicolumn{6}{|l|}{ Radiation } \\
\hline Antergrade & 2.7 & 0.8 & 1.8 & 5.6 & \multirow[t]{2}{*}{0.000} \\
\hline Retrograde & 0.4 & 0.1 & 0.30 & 0.70 & \\
\hline \multicolumn{6}{|l|}{ Blood loss } \\
\hline Antergrade & 0.58 & 0.10 & 0.45 & 0.85 & \multirow[t]{2}{*}{0.015} \\
\hline Retrograde & 0.50 & 0.12 & 0.40 & 0.80 & \\
\hline \multicolumn{6}{|l|}{ Entry time } \\
\hline Antergrade & 17.2 & 6.9 & 10.0 & 35.0 & \multirow[t]{2}{*}{0.000} \\
\hline Retrograde & 5.3 & 1.2 & 3.0 & 8.0 & \\
\hline \multicolumn{6}{|l|}{ Wound length } \\
\hline Antergrade & 7.6 & 1.4 & 5.0 & 10.0 & \multirow[t]{2}{*}{0.000} \\
\hline Retrograde & 5.0 & 0.61 & 4.0 & 6.0 & \\
\hline \multicolumn{6}{|l|}{ Sequence } \\
\hline Antergrade & 0.50 & 1.1 & 0.0 & 4.0 & \multirow[t]{2}{*}{0.055} \\
\hline Retrograde & 0.0 & 0.0 & 0.0 & 0.0 & \\
\hline
\end{tabular}

Compared to the classic antegrade portal, it had a

medulla in a specific situation of femoral nonunion after failed plating, and compared it to the classic antegrade portal.

The weakness of this study is the weak quasi-randomization, and the small number of cases. The strengths are the prospective randomized nature, the numerous statistically significant differences between groups, and the success of obtaining the centric entry in all cases. $69.1 \%$ shorter portal time; $13 \%$ less blood loss; $85 \%$ reduction in fluoroscopy time; and $34 \%$ reduction of entry wound length. The ideal portal was obtained in all retrograde cases with no angulation, eccentricity, or comminution.

The new technique is easier to perform with numerous advantages. It provides a better alternative surgical 


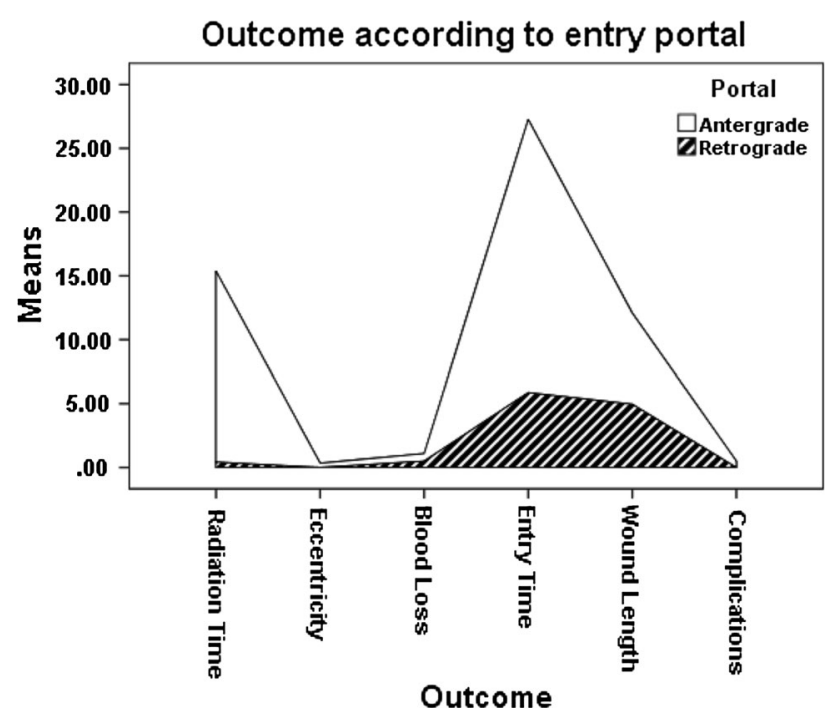

Table 6 Significance of factors involved in development of frontal angulation

\begin{tabular}{ll}
\hline Dependent variable & Sig. \\
\hline Eccentricity & 0.014 \\
Level & 0.424 \\
Shape & 0.194 \\
OTA type & 0.360 \\
Comminution & 0.048 \\
\hline
\end{tabular}

Fig. 3 The final comparative outcome in both groups is plotted

Fig. 4 Two examples of eccentric portal of entry in antegrade cases: a varus angulation at nonunion site due to too lateral portal of entry into the greater trochanter. b Valgus angulation at nonunion site due to too medial portal of entry. While c, the proper portal of entry, was obtained using the retrograde technique with centralization of the nail inside the medullary canal
Table 5 Demographics of cases of frontal angulation
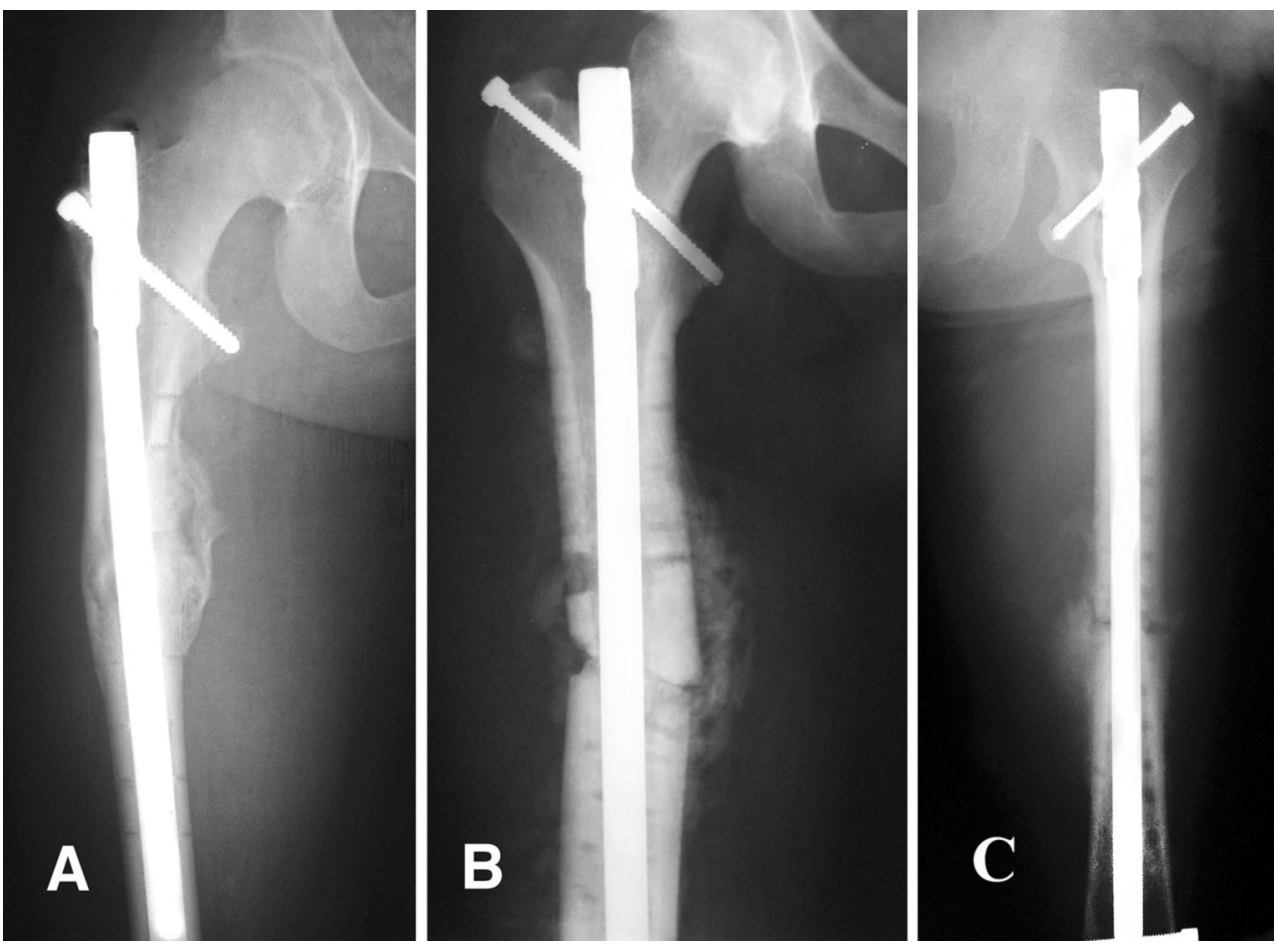

\begin{tabular}{llllll}
\hline Eccentricity & Level & Shape & OTA type & Comminution & Frontal angulation \\
\hline Medial & Middle third & Oblique & $32-\mathrm{A} 3.2$ & Comminuted & 5.00 \\
Lateral & Upper third & Oblique & $32-\mathrm{B} 1.1$ & Comminuted & 6.00 \\
Lateral & Middle third & Spiral & $32-\mathrm{A} 1.2$ & Non-comminuted & 5.00 \\
Lateral & Middle third & Transverse & $32-\mathrm{A} 3.3$ & Comminuted & 4.00 \\
\hline
\end{tabular}


Table 7 Pearson test

\begin{tabular}{lll}
\hline Parameter & Pearson correlation value & Sig. (two-tailed) \\
\hline Radiation & -0.886 & 0.000 \\
Eccentricity & -0.332 & 0.034 \\
Blood loss & -0.379 & 0.015 \\
Entry time & -0.782 & 0.000 \\
Wound length & -0.777 & 0.000 \\
Sequence & -0.349 & 0.025 \\
\hline
\end{tabular}

technique than the classic antegrade portal in femoral nonunion after plate failure or similar conditions requiring open nailing.

\section{Compliance with ethical standards}

Ethical standards This prospective comparative study was performed after obtaining Institutional Review Board approval, and an informed written consent. This study has been performed in accordance with the ethical standards in the 1964 Declaration of Helsinki and with relevant regulations of the US Health Insurance Portability and Accountability Act (HIPAA).

\section{Conflict of interest None.}

Open Access This article is distributed under the terms of the Creative Commons Attribution 4.0 International License (http://crea tivecommons.org/licenses/by/4.0/), which permits unrestricted use, distribution, and reproduction in any medium, provided you give appropriate credit to the original author(s) and the source, provide a link to the Creative Commons license, and indicate if changes were made.

\section{References}

1. Ricci WM, Gallagher B, Haidukewych GJ (2009) Intramedullary nailing of femoral shaft fractures: current concepts. J Am Acad Orthop Surg 17:296-305
2. Winquist RA (1993) Locked femoral nailing. J Am Acad Orthop Surg 1:95-105

3. Linke B, Ansari Moein C, Bosl O, Verhofstad MH, van der Werken C, Schwieger K, Ito K (2008) Lateral insertion points in antegrade femoral nailing and their influence on femoral bone strains. J Orthop Trauma 22:716-722. doi:10.1097/BOT. 0b013e318189369e

4. Charopoulos I, Giannoudis PV (2009) Ideal entry point in antegrade femoral nailing: controversies and innovations. Injury 40:791-794. doi:10.1016/j.injury.2009.06.002

5. Johnson KD, Tencer AF, Sherman MC (1987) Biomechanical factors affecting fracture stability and femoral bursting in closed intramedullary nailing of femoral shaft fractures, with illustrative case presentations. J Orthop Trauma 1:1-11

6. Gausepohl T, Pennig D, Koebke J, Harnoss S (2002) Antegrade femoral nailing: an anatomical determination of the correct entry point. Injury 33:701-705

7. Tucker MC, Schwappach JR, Leighton RK, Coupe K, Ricci WM (2007) Results of femoral intramedullary nailing in patients who are obese versus those who are not obese: a prospective multicenter comparison study. J Orthop Trauma 21:523-529. doi:10. 1097/BOT.0b013e31813347ac

8. Prasarn ML, Cattaneo MD, Achor T, Ahn J, Klinger CE, Helfet DL, Lorich DG (2010) The effect of entry point on malalignment and iatrogenic fracture with the Synthes lateral entry femoral nail. J Orthop Trauma 24:224-229. doi:10.1097/BOT. 0b013e3181bedcc1

9. Tupis TM, Altman GT, Altman DT, Cook HA, Miller MC (2012) Femoral bone strains during antegrade nailing: a comparison of two entry points with identical nails using finite element analysis. Clin Biomech (Bristol Avon) 27:354-359. doi:10.1016/j.clin biomech.2011.11.002

10. Schottel PC, Hinds RM, Lazaro LE, Klinger C, Ni A, Dyke JP, Helfet DL, Lorich DG (2015) The effect of antegrade femoral nailing on femoral head perfusion: a comparison of piriformis fossa and trochanteric entry points. Arch Orthop Trauma Surg 135:473-480. doi:10.1007/s00402-015-2169-y 